(C) 2019. This manuscript version is made available under the CC-BY-NC-ND 4.0 license http://

creativecommons.org/licenses/by-nc-nd/4.0/

\title{
Risk Matrix Driven Supply Chain Risk Management: Adapting Risk Matrix Based Tools To Modelling Interdependent Risks and Risk Appetite
}

\author{
Abroon Qazi, Pervaiz Akhtar
}

\begin{abstract}
There is a major research gap of developing a supply chain risk management process integrating risk appetite of the decision maker and all stages of the risk management process within an interdependent network of systemic risks. We introduce an iterative process, namely risk matrix driven supply chain risk management, to bridge this gap. We make use of the recently introduced concept of utility indifference curves based risk matrix to capture the risk attitude of the decision maker. We also present algorithms for assessing and mitigating interdependent risks for risk-neutral and risk-averse/seeking decision makers and demonstrate the application of our proposed process through a simulation study. Utilising the method of cost-benefit analysis within an interdependent setting of interacting risks and risk mitigation strategies, we also propose a second approach that can help a decision maker determine a set of Pareto-optimal risk mitigation strategies and select optimal solutions subject to the budget constraint and specific risk appetite.
\end{abstract}

Keywords: Supply chain risk management, systemic risks, risk appetite, utility indifference curves, risk matrix, algorithms

\section{Introduction}

Risk management is a continuous process comprising sequential stages of risk identification, risk analysis, risk evaluation, risk treatment and risk monitoring (SA, 2009). Supply chain risk management (SCRM) is the "implementation of strategies to manage both everyday and exceptional risks along the supply chain based on continuous risk assessment with the objective of reducing vulnerability and ensuring continuity" (Wieland \& Wallenburg, 2012, pp. 890-891). Adapting the established risk management framework (SA, 2009), researchers have been proposing various SCRM frameworks (Tummala \& Schoenherr, 2011; Heckmann et al., 2015, Ho et al., 2015). Besides these frameworks, a number of models and tools have been developed focusing on different stages of the SCRM process Fahimnia 10 et al. 2015).

Supply chain risks have been generally classified into independent categories (Rao \& Goldsby, 2009 ) like physical, financial, information, relational and innovation (Cavinato, 2004, Spekman \& Davis, 2004). The same independent categories of risks are adopted and reflected in the conventional risk matrix based tools used by the practitioners (Norrman \& Jansson, 2004, Khan et al., 2008). Limited articles in the literature on risk management in general (Ackermann et al., 2014) and SCRM 
in particular (Garvey et al., 2015, Qazi et al., 2017) have focused on the shortcoming of conventional techniques of risk identification and emphasised the need for capturing systemic interactions between risks. Risk assessment/evaluation and risk treatment following the conventional risk identification techniques yield sub-optimal solutions as these techniques fail to account for complex dynamics across the risks and risk sources (Ackermann et al. 2014).

Risk appetite of the decision maker drives the tolerance level with respect to the acceptance of risks. According to Heckmann et al. (2015, p. 127): “The decision maker's degree of acceptance with respect to the deterioration of target-values defines his attitude towards supply chain risk. Riskaverse supply chain managers only accept a minor deterioration of target values of an efficiency- (or effectiveness-) based supply chain goal in exchange for the adherence or increase of an effectiveness(or efficiency-) based supply chain goal. Risk-seeking decision makers, however, accept higher degrees of value deterioration of a specific goal in exchange for the adherence or increase of an opposite one. Risk-neutral supply chain managers prefer neither of the two objective types". Very few frameworks in SCRM have captured the risk appetite of the decision maker (Knemeyer et al., 2009; Lavastre et al., 2012); however, to the best of the authors' knowledge, no existing study has ever investigated designing a risk management framework within a network setting of interacting risks driven by the risk appetite of the decision maker.

Integration of utility indifference curves within the risk matrix has been recently introduced in the literature on risk management that results in discretising the risk matrix into five risk zones: Negligible -no need for further concern; Acceptable -need for monitoring the risks with no investment; Controllable -need for adopting emergency plans; Critical -need for mitigating risks as long as the benefits exceed the costs; and Unacceptable -need for bringing the risks down to the critical level at any cost (Ruan et al. 2015). However, the following question remains un-answered so far: Whether the concept of utility indifference curves based risk matrix for assessing independent risks can be developed further to account for interdependent risks?

Recently, few studies have focused on proposing probabilistic supply chain risks for assessing and managing interdependent risks. Selection of optimal risk mitigation strategies has also gained limited attention both in the literature on risk management in general (Spackova \& Straub, 2015) and SCRM in particular (Tuncel \& Alpan, 2010; Micheli et al., 2014; Aqlan \& Lam, 2015) but the main challenge 45 is to develop these studies further to capture the risk appetite of the decision maker as well. The main research question driving our research project is: How can we design a SCRM process integrating the systemic interaction between risks and the risk appetite of the decision maker?

In this study, we aim to contribute to the field of SCRM by introducing a major research gap that has gained limited attention so far. Furthermore, we introduce a new risk management process, namely risk matrix driven supply chain risk management (RMSCRM), and demonstrate why it is important 
to close the identified research gap and to follow our proposed process. We present algorithms for assessing and mitigating interdependent risks with regard to the risk-neutral and risk-averse/seeking decision makers. We transform the conventional risk matrix in order to make it compatible for assessing interdependent risks in relation to utility indifference curves specific to the decision maker. We also introduce a second approach to help supply chain risk managers identify the Pareto-optimal set of risk mitigation strategies and select optimal solutions subject to the budget constraint and specific risk appetite.

The remainder of this paper is organised as follows: A brief review of the relevant literature is presented in section 2. Background knowledge about the Expected Utility Theory (EUT) and a motivational example are described in section 3 and section 4, respectively. The proposed risk matrix based process and approach are described in section 5. The application of the proposed risk matrix based process is demonstrated through a simulation study in section 6 . The second approach of selecting optimal strategies without using the risk matrix is introduced and illustrated in section 7 . Merits and limitations of the proposed approaches are discussed in section 8. Finally, we conclude our paper with important findings and present future research themes in section 9 .

\section{Literature Review}

A number of articles focusing on the SCRM process/framework and literature reviews were critically analysed in order to address the research question. In this section, we will present a brief overview of the existing SCRM frameworks and delineate a major research gap meriting extensive research.

Harland et al. (2003) developed a supply network risk management tool and applied it to the electronics industry through conducting four case studies. The main merit of the tool is its exclusive focus on collaborative risk management achieved through engaging the stakeholders across a supply network. Building on the same concept of network-wide management of risks, Hallikas et al. (2004) introduced a risk management process integrating different perspectives of supply chain actors and emphasised the need for adopting systems approach in order to understand the complex dynamics across a network. A systems-oriented SCRM process is also introduced by Oehmen et al. (2009) that captures the interdependency between risks. Advocating the need for adapting the degree of risk management with regard to the contextual factors, Giunipero \& Eltantawy (2004) introduced a risk management framework contingent on four determinants: degree of product technology; need for security; importance of the supplier; and purchaser's prior experience with the situation. The Supply Chain Operations Reference (SCOR) model has been modified and considered as an important framework for managing supply chain risks (Sinha et al., 2004; Rotaru et al., 2014). The main limitation of the aforementioned studies and other risk management frameworks proposed by Manuj \& Mentzer (2008), Khan et al. (2008) and Tummala \& Schoenherr (2011) is their limited focus on capturing the 
interdependency between risks.

Only two of the selected studies (Knemeyer et al., 2009, Lavastre et al., 2012) considered the risk appetite of the decision maker as an important factor and included it in the SCRM framework. Although risk attitude has been considered in the modelling framework of a number of studies as mentioned in the literature review conducted by Heckmann et al. (2015), these articles fail to meet the selection criterion of this study because of their focus on a specific stage of the risk management process.

Among the quantitative studies, Tuncel \& Alpan (2010) used a timed Petri nets framework to model and analyse a supply chain which is subject to various risks. They used Failure Modes and Effects Analysis (FMEA) to identify important risks having higher values of Risk Priority Number (RPN). Elleuch et al. (2014) proposed a comprehensive risk management process integrating the techniques of FMEA, design of experiments, Analytical Hierarchy Process (AHP) and a desirability function approach. Micheli et al. (2014) and Aqlan \& Lam (2015) introduced optimisation-based techniques for selecting optimal risk mitigation strategies. Although all the mentioned quantitative studies consider interdependency between risks and strategies, critical aspect of modelling interdependency between risks and the risk appetite of a decision maker is ignored. Utilising Bayesian Belief Networks (BBNs), Garvey et al. (2015) introduced risk measures for prioritising interdependent supply chain risks assuming a risk-neutral decision maker whereas Qazi et al. (2017) introduced probabilistic supply chain risk measures to prioritise interdependent risks and strategies. Although one of the measures introduced captures risk-averse appetite, the entire risk management process does not explicitly model the risk attitude of a decision maker.

A number of articles focusing on literature reviews were also reviewed (Jüttner et al., 2003, Tang, 2006; Khan \& Burnes, 2007; Natarajarathinam et al., 2009; Rao \& Goldsby, 2009; Ponomarov \& Holcomb, 2009; Olson \& Wu, 2010; Tang \& Nurmaya Musa, 2011; Ghadge et al., 2012; Colicchia \& Strozzi, 2012; Sodhi et al., 2012; Ho et al., 2015; Heckmann et al., 2015) and it was revealed that only two studies have emphasised the need for modelling interdependency between risks hereby: “... developing structured and systematic tools for risk identification and assessment that explicitly consider the dynamic interactions among supply chain partners and among risk sources" (Colicchia \& Strozzi, 2012, p. 412), and “... While focusing on a particular risk type has its advantages, interdependencies and interrelationships among various risk types is certainly an issue that needs to be further explored. Investigating the joint impact of such risks can lead to better management of supply chains than treating each risk type in isolation" (Ho et al., 2015, p. 5060).

Similarly, despite the fact that existing SCRM frameworks fail to integrate all stages of the risk management process within an interdependent setting of risks and strategies, only two articles have highlighted the importance of conducting research in this direction: "The multidimensional perspective 


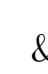

focusing on management processes, risk dimensions, impact flows and mitigation alternatives needs to be studied in whole" (Ghadge et al., 2012, p. 329), and "As there is a significant relationship between all SCRM processes, more attention should be given to legitimately integrated processes instead of individual or fragmented processes" (Ho et al. 2015, p. 5053). Another major issue concerning these studies is their limited focus on the need for integrating risk appetite in the risk management process as only Heckmann et al. (2015) argue that "More advanced (context-sensitive) approaches especially with respect to the risk attitude of the decision maker and with respect to the environment of the affected supply chain are needed" (Heckmann et al., 2015, p. 130). A critical review of the selected articles focusing on the SCRM process/framework and literature reviews reveal a finding that an integrated risk management framework considering the interdependency between risks and mitigation strategies and the risk appetite of a decision maker has neither been explored nor mentioned as a research gap for directing future research.

\section{Expected Utility and Decision Making Under Uncertainty}

Within the context of decision making under uncertainty, risk can be related to a utility function that reflects the preference of a decision maker with regards to various possible losses or consequences of a decision. According to Aven (2012), if $X$ and $u(X)$ represent the possible outcomes associated with a decision and utility function respectively, then the expected utility $E[u(X)]$ provides a decision criterion where probabilities and a utility function are assigned on the set of outcomes and a rational decision maker selects an action that maximises the expected utility value. The utility function represents the risk attitude of a decision maker where a risk-neutral decision maker would be indifferent between two outcomes having the same expected value and a risk-seeking (averse) individual would consider uncertainty to be an (un)favorable phenomenon. The following equations (inequalities) represent different risk attitudes (Aven, 2012):

$$
\begin{aligned}
& \text { Risk-neutral : } E[u(X)]=u(E[X]) \\
& \text { Risk-averse : } E[u(X)]<u(E[X])
\end{aligned}
$$

$$
\text { Risk-seeking : } E[u(X)]>u(E[X])
$$

\footnotetext{
under uncertainty, it is not so much used in practice mainly because of the difficulty associated with under uncertainty, it is not so much used in practice mainly because of the difficulty associated with
assigning utility values to all possible outcomes (Aven \& Kristensen, 2005). Also, a decision maker in

For gaining an insight into developing the utility function, interested readers may consult Kainuma \& Tawara (2006). Although EUT provides a standardised normative framework to make decisions
} 
many cases would not seek to maximise the expected utility but rather solutions yielding satisfactory theory, Ruan et al. (2015) introduced a three step process for integrating risk attitude in the risk matrix by: (a) describing risk attitudes of decision makers by utility functions; (b) introducing utility indifference curves and embedding these into the risk matrix; and (c) discretising utility indifference 

specific to the four indifference curves are assumed as $-695,-521,-347$ and -174 , respectively. 


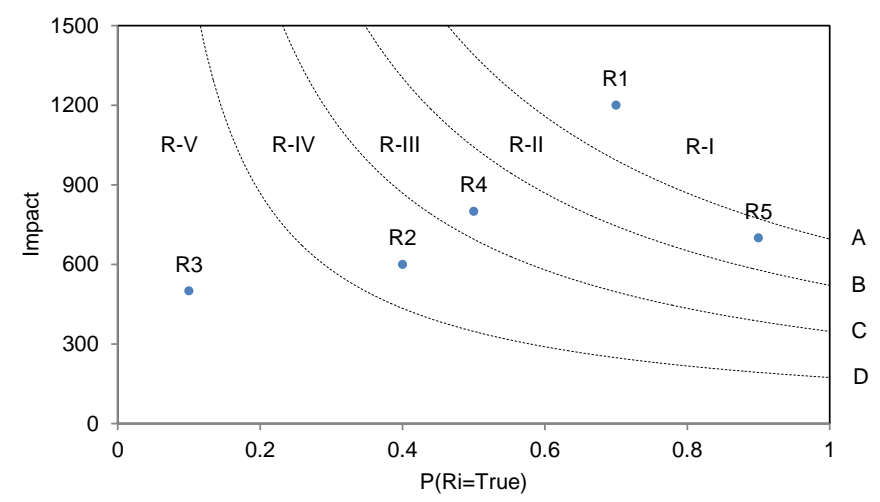

Figure 1: Utility indifference curves based risk matrix.

As $R 1$ is an unacceptable risk, it must be mitigated at any cost. $R 5$ must be mitigated if the benefit exceeds the cost. We can identify a strategy or combinations of strategies that would either reduce

the probability or impact of a risk or a set of risks. It is very easy to conduct the risk treatment as we only need to evaluate the benefits through executing simple arithmetic operations and weigh these against the total cost of implementing strategies. Therefore, we can prioritise risks and select optimal strategies through following a sequential risk management process. During the risk monitoring stage, any new risk(s) and/or changes in the parameters of existing risks must be incorporated in the risk matrix.

\subsection{Motivation for Developing a New Process}

Now let us consider that instead of a set of independent risks, we are dealing with a network of risks where there are interdependencies between risks and a risk might have a (positive or negative) correlation with another risk or a set of risks. Similarly, a mitigation strategy can have an association with multiple risks or multiple strategies can influence a single risk. Existing frameworks fail to account for evaluation and treatment of such network of risks. In the case of interdependent risks, we need to marginalise the probability values through assigning conditional probability values to the risks. The existing risk matrix based tools are not capable of projecting the criticality of interdependent risks. Furthermore, the criterion for conducting cost-benefit analysis for the network of risks and potential strategies taking into account the risk appetite of a decision maker and linking it back to the performance of individual risks on the risk matrix is not established. In the case of risk treatment, we can no longer rely on simple mathematical operations as each potential strategy or a combination of strategies must be linked to the risk network and the marginal probability values of risks must be re-evaluated and the resulting risks mapped again on the risk matrix. Therefore, it makes the process as iterative rather than sequential.

EUT being widely used in decision making under uncertainty provides a systematic approach of evaluating optimal strategies (Aven, 2015); however, even for a very simple network of 5 risks and 5 
strategies, a total of 1024 values must be elicited from the decision maker with regard to the utility of different combinations of risks and strategies. Furthermore, as reported in the literature on risk

\section{Proposed Risk Matrix Driven Supply Chain Risk Management Process} researchers and practitioners (Khan et al., 2008). Although the description of terms and concepts used in the framework is controversial (Aven, 2011), our focus is limited to the stages involved in the process. The proposed process is shown in Figure 2, Instead of treating risks in isolation, we introduce the concept by developing a risk network. The process starts with the specification of context in terms of defining the boundary of a supply chain/network and identifying the stakeholders involved in the risk management process.

Risk network identification is a critical stage where there is a need for bringing a paradigm shift as the existing literature is rife with conventional tools and techniques of identifying risk categories and the concept of developing causal risk paths/risk network has gained limited attention (Garvey et al. 2015). Besides identifying the risks and risk sources, potential risk mitigation strategies must also be included within the network. Risk network analysis involves determining the (conditional) probability values and loss values associated with risks subject to the implementation of specific risk mitigation strategies.

In the risk network evaluation stage, there is a need to explore new risk measures that can be computed easily and are capable of capturing the network-wide impact of risks. The measures are also influenced by the risk appetite. In addition to registering the holistic impact of risks within the network setting, there is also a need for visualising the impact of each risk on the network of risks and ensuring that all risks are mitigated to the required level. Therefore, a modified risk matrix capable of evaluating interdependent risks coupled with the mapping of utility indifference curves (Ruan et al., 2015) must be developed and consulted for risk network evaluation as shown in Figure 3 .

As the objective of our research is to introduce a risk management process for interdependent risks, we are not focusing on the techniques for establishing the risk appetite of a decision maker and mapping utility indifference curves on the modified risk matrix. The procedure proposed by Ruan et al. (2015) can be utilised for implementing the proposed process. However, we are not dealing with the discretisation of risk matrix because of the probability and loss values used in the proposed risk management process. Appropriate risk measures representing the network wide holistic impact of 


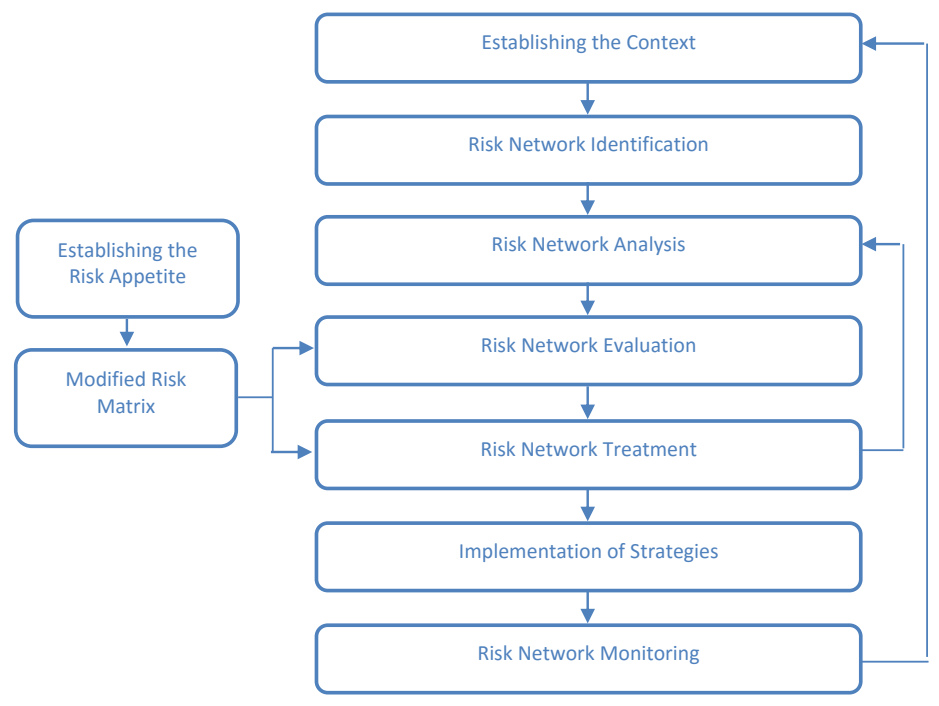

Figure 2: Risk matrix driven supply chain risk management (RMSCRM).
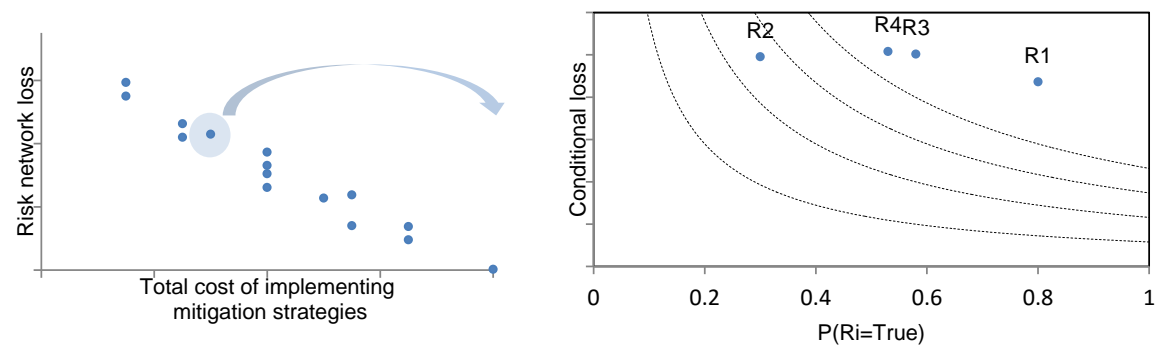

Figure 3: Mapping from risk network evaluation to modified risk matrix. 
risks can be used for risk analysis/evaluation and corresponding to each combination of strategies, the configuration of individual risks $(R 1, R 2, R 3, R 4)$ can be mapped on the modified risk matrix. The matrix is bounded by the upper limit of loss beyond which a risk irrespective of its probability value

Risk network treatment deals with the evaluation of different combinations of risk mitigation strategies within the network setting. The modified risk matrix provides a lens to evaluate the efficacy of strategies and establish if additional strategies must be implemented. The proposed process flow is in contrast with the one established in extant literature as instead of following a unidirectional flow, it is an iterative process where evaluation of each combination of strategies necessitates re-assessing and re-evaluating the risk network. The iterative process results in the selection of an optimal combination of strategies that not only considers the network-wide holistic effect of these strategies but also yields an acceptable configuration of risks mapped on the modified risk matrix. The matrix also helps in identifying critical risks that must be monitored periodically. After determining the optimal combination of strategies, these are implemented and as risk management is a continuous process, there is a need for continuously monitoring risks and updating the risk network on a regular basis.

\subsection{Proposed Approach}

\subsubsection{Modelling Assumptions}

The model is based on the following assumptions:

- Supply chain risks, corresponding sources and potential mitigation strategies are known and these can be modelled as an acyclic directed graph.

- All random variables and risk mitigation strategies are represented by binary states.

- Conditional probability values for the risks and associated losses can be elicited from the stakeholders and the resulting network represents close approximation to the actual perceived risks and interdependency between different risks.

- Cost associated with each potential risk mitigation strategy is known.

\subsubsection{Supply Chain Risk Network}

A discrete supply chain risk network $R N=(X, G, P, L, U, C)$ is a six-tuple consisting of:

- a directed acyclic graph $(D A G), G=(V, E)$, with nodes, $V$, representing discrete risks and risk sources, $X_{R}$, discrete risk mitigation strategies, $X_{S}$, and directed links, $E$, encoding dependence relations,

- a set of conditional probability distributions, $P$, containing a distribution, $P\left(X_{R_{i}} \mid X_{p a\left(R_{i}\right)}\right)$, for each risk and risk source, $X_{R_{i}}$, 
- a set of loss functions, $L$, containing one loss function, $l\left(X_{p a(V)}\right)$, for each node $v$ in the subset $V_{l} \in V$ of loss nodes,

- a set of utility functions, $U$, containing one utility function, $u\left(X_{p a(V)}\right)$, for each node $v$ in the subset $V_{u} \in V$ of utility nodes,

- a set of cost functions, $C$, containing one cost function, $c\left(X_{p a(V)}\right)$, for each node $v$ in the subset $V_{c} \in V$ of cost nodes.

Risk network expected loss, $R N E L(X)$, is given by (Qazi et al., 2015a):

$$
R N E L(X)=\prod_{X_{v} \in X_{R}} P\left(X_{v} \mid X_{p a(v)}\right) \sum_{w \in V_{L}} l\left(X_{p a(w)}\right)
$$

Expected utility for loss, $E U(X)$, is given by (Qazi et al., 2015b):

$$
E U(X)=\prod_{X_{v} \in X_{R}} P\left(X_{v} \mid X_{p a(v)}\right) \sum_{w \in V_{L}} u\left(X_{p a(w)}\right)
$$

Risk network expected utility, $R N E U\left(X, C\left(X_{S_{i}}\right)\right)$ or $R N E U$, is given by:

$$
R N E U=f\left(E U(X), C\left(X_{S_{i}}\right)\right)
$$

where $X_{S_{i}}$ is a combination of potential strategies.

\subsubsection{Risk Measure}

We make use of a risk measure namely Risk Network Expected Loss Propagation Measure (RNELPM) in order to evaluate the relative contribution of each supply chain risk towards the loss propagation across the entire network of risks. RNELPM is the relative contribution of each risk factor to the propagation of loss across the entire network of supply chain risks given the scenario that the specific risk is realised (Qazi et al., 2017).

$$
R N E L P M_{X_{R_{i}}}=\operatorname{RNEL}\left(X \mid X_{R_{i}}=\text { true }\right) \cdot P\left(X_{R_{i}}=\text { true }\right)
$$

\subsubsection{Risk Configuration Metric}

Risk configuration metric $(R C M)$ represents the preference of a decision maker with regard to the configuration of risks on the modified risk matrix specific to a particular combination of available strategies represented by $X_{S_{i}}$. A pure qualitative metric focusing on the relative number of risks within each risk zone may be represented as follows:

$$
R C M_{X_{S_{i}}}=\frac{n_{1} \cdot a_{1}+n_{2} \cdot a_{2}+n_{3} \cdot a_{3}+n_{4} \cdot a_{4}+n_{5} \cdot a_{5}}{N}
$$


where $n_{i}$ and $a_{i}$ represent the number of risks in the risk zone $i$ and the criticality significance of risk zone $i$ on a normalised scale, respectively,

$N$ is the total number of risks.

However, we consider the following risk metric to be appropriate as defined over a range of continuous values:

$$
R C M_{X_{S_{i}}}=\sum_{X_{R}}-u\left(R N E L_{X_{S_{i}}}\left(X \mid X_{R_{i}}=\text { true }\right)\right) \cdot P\left(X_{R_{i}}\right)_{X_{S_{i}}}
$$

Equation 11 is the discretised form of Equation 12 where each risk zone is assigned a preference value and any pair of risks located in the same zone would have the same value. The main purpose of using Equation 12 is not to treat the individual utility functions of risks as mutually independent and add these together, but rather to evaluate the preference of the risk configuration specific to a combination of strategies with respect to the utility indifference curves mapped. Therefore, $R C M_{X_{S_{i}}}$ is a preference measure to help the decision maker prioritise between two different combinations of strategies with regards to the distribution of risks on the risk matrix. Unlike the expected utility approach where all possible combinations of outcomes are evaluated, we only consider the possibility that a particular risk materialises and register the impact of all risks in turn. A combination of strategies yielding an optimal aggregate value of these instantiations subject to the constraints of risk zones and cost-effectiveness is finally selected.

The normalised risk metric is defined as follows:

$$
R \bar{C} M_{X_{S_{i}}}=1-\frac{R C M_{X_{S_{i}}}}{\max \left(R C M_{X_{S}}\right)}
$$

where $R C M_{X_{S}}$ is the entire set of $R C M$ values for all possible combinations of strategies.

\subsubsection{Problem Setting}

Given five zones of risk prioritisation in the modified risk matrix segregated by the utility indifference curves $\left(p_{i} * u\left(l_{i}\right)=-A_{j} \forall X_{R_{i}}\left(p_{i}, l_{i}\right)\right.$ on the curve $j$ ) and the threshold loss, $l^{*}$ (defining the portion of unacceptable zone represented by the area of risk matrix above that threshold line) where the set $\left(A_{1}, A_{2}, A_{3}, A_{4}\right)$ representing constant values arranged in descending order corresponds to the set of curves segregating the five risk zones: unacceptable; critical; controllable; acceptable; and negligible.

What is the optimal set of combinations of strategies, $\bar{S}_{p}=\left(\bar{S}_{p_{1}}, \ldots, \bar{S}_{p_{r}}\right)$ with associated set of total cost of mitigation strategies $C\left(\bar{S}_{p}\right)=\left(C\left(\bar{S}_{p_{1}}\right), \ldots, C\left(\bar{S}_{p_{r}}\right)\right)$ for the entire risk network such that each $\bar{S}_{p_{i}}$ (comprising a specific combination of potential strategies) yields the (maximum) minimum value of the (normalised) risk configuration metric $(R C M)$ subject to the risk mitigation requirements of each risk zone? 


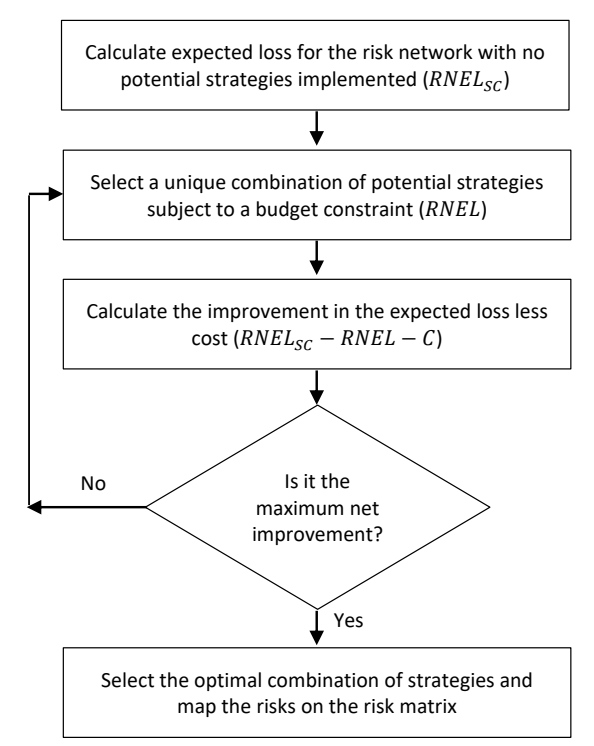

Figure 4: Flow chart for selecting optimal strategies specific to a risk-neutral decision maker.

\subsubsection{Proposed Algorithms}

We propose two different algorithms for managing risks corresponding to the risk-neutral and risk-averse/risk-seeking decision makers as shown in Algorithm A.4 and Algorithm A.5, respectively. Although the algorithms make use of our proposed risk measure, these are still adaptable for incorporating other risk measures. We have intentionally not included the stage of risk identification as a relevant algorithm already exists for developing the risk network (Garvey et al., 2015). The flow charts specific to Algorithm A.4 and Algorithm A.5 are shown in Fig 4 and Fig 5 , respectively.

\subsubsection{Modelling Process}

The following steps must be pursued in developing a BBN based risk network of interacting supply chain risks and risk mitigation strategies:

- Define the boundaries of the supply network and identify stakeholders.

- Identify a network of key risks, corresponding risk sources and potential risk mitigation strategies on the basis of input received from each stakeholder through interviews and/or focus group sessions.

- Refine the qualitative structure of the resulting network involving all stakeholders.

- Elicit (conditional) probability values, loss (utility) values resulting from risks and cost associated with implementing each potential mitigation strategy and populate the BBN with all values.

- Run the model and follow Algorithms A.4 and A.5 specific to a risk-neutral and risk-averse/riskseeking decision maker, respectively for assessing and treating risks.

- Validate the model output involving stakeholders. 


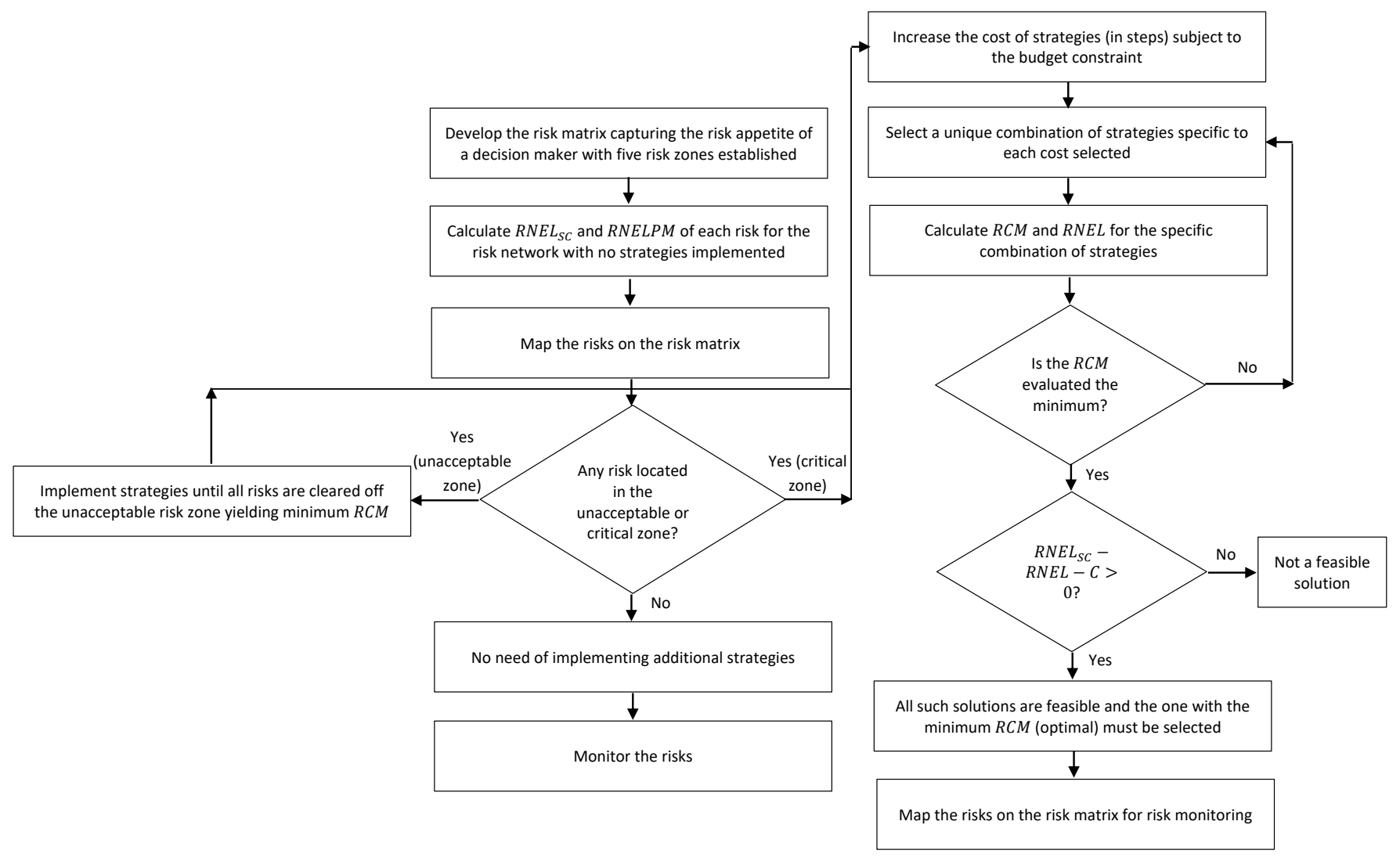

Figure 5: Flow chart for selecting optimal strategies specific to a risk-averse (seeking) decision maker.

\subsection{Illustrative Example: Demonstration of Key Concepts}

In order to demonstrate the key concepts introduced, we present a simple network comprising five risks $(\mathrm{Ri})$ and four potential risk mitigation strategies $(\mathrm{Si})$ as shown in Figure 6. It is assumed that each risk is associated with a loss value of 100 units and each strategy can be implemented at a cost of 30 units. Each risk is considered to have binary states: True (T) or False (F). Similarly, each mitigation strategy is assumed to be in one of the binary states: Yes $(\mathrm{Y})$ or No $(\mathrm{N})$. The (conditional) probability values are shown in Table A.1. The shaded cells represent the (conditional) probability values once the corresponding mitigation strategy is selected. It is interesting to consider positive correlation of $S 1$ with R2.

\subsubsection{Risk-Neutral Decision Maker}

A risk-neutral decision maker interested in maximising reduction in the cost adjusted risk network expected loss does not account for the relative importance of each risk in terms of its relative position on the modified risk matrix. The decision maker would only select a combination of strategies and make an investment if there is an increase in the reduction of risk network expected loss less cost. Under the standard configuration, the risks are evaluated with respect to the existing strategies once none of the potential strategies are selected. All possible combinations of potential strategies $(S 1, S 2$, $S 3, S 4)$ are shown in Table A.2. 


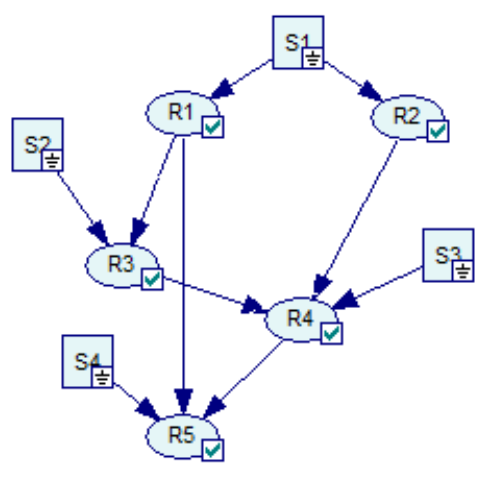

Figure 6: Risk network modelled in GeNIe.

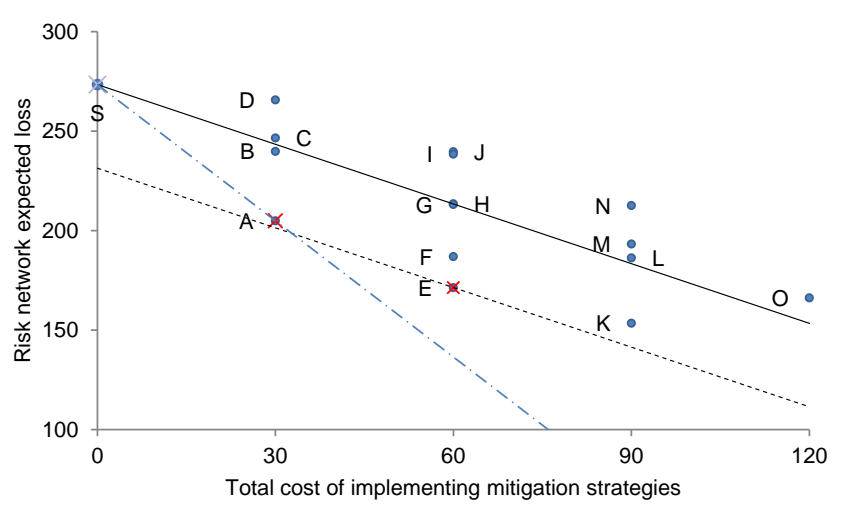

Figure 7: Identification of optimal combinations of strategies.

The relative performance of each combination of strategies is mapped in Figure 7. Each point represents a particular combination of strategies with corresponding cost and risk network expected loss. The solid line represents the threshold where the reduction in risk network expected loss is just equal to the cost of implementing strategies. The points (above) below this line represent all such combinations which are (in)feasible.

The dotted line contains the optimal solution (point E) yielding maximum reduction in the network expected loss less cost whereas the dashed line contains the optimal solution (point A) following the criterion of maximising benefit to cost ratio. Although point $\mathrm{K}$ is a feasible solution, it is not optimal as it fails to yield a greater reduction in the cost adjusted network expected loss relative to that of point E. A cross represents an optimal solution. The decision maker will select point A if the available budget is less than 60 units but at least 30 units whereas for a budget greater than and inclusive of 60 units, point $\mathrm{E}$ is the optimal solution.

\subsubsection{Risk-Averse Decision Maker}

In the case of a risk-averse decision maker, we assume the utility function as represented by Equation 395 14. We also assume that the upper threshold for the loss value is 500 units. Similarly, the selected $u\left(l^{\prime}\right)$ 


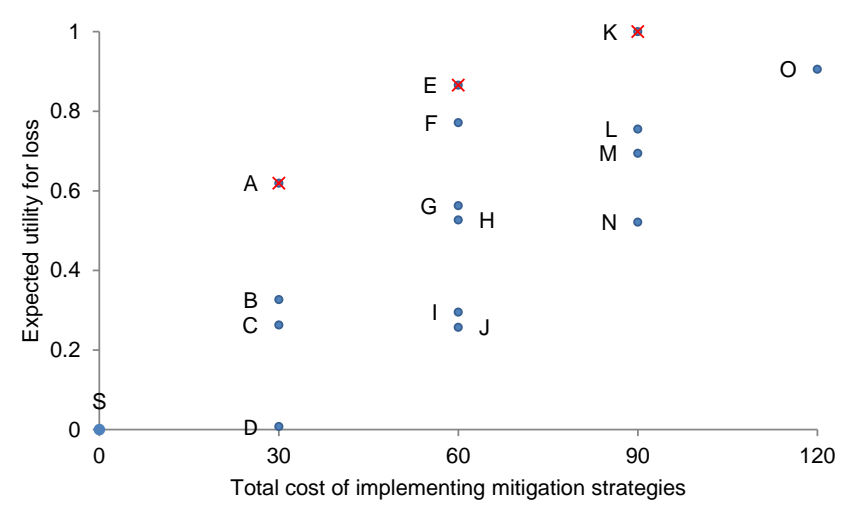

Figure 8: Expected utility for loss corresponding to various strategies.

values corresponding to the four utility indifference curves are $-200,-150,-100$ and -50 , respectively.

$$
u(l)=-(l)^{2}
$$

Maximising Risk Network Expected Utility. There are two ways of evaluating the risk network expected utility. We can either combine the cost of strategies and loss associated with different combinations of risks and strategies, or evaluate utility of loss and utility of cost separately and combine these together using an appropriate function and a consistent scale. The first approach needs an input of 512 values as it is not possible to aggregate the individual utility values because of utility being a non-linear function in this example. Using the second approach, we can calculate the expected utility value for loss corresponding to different strategies needing only 32 values as shown in Figure 8 . Points A, E and $\mathrm{K}$ are the optimal combinations of strategies considering expected utility for loss, however, selection of optimal strategies corresponding to risk network expected utility (function of loss and cost) depends on the relative importance of expected utility for loss $(w)$ and utility for cost $(1-w)$ as shown in Equation 15. Importantly, the scales used for the two functions must be consistent. Point O can never be an optimal solution under any preference setting.

$$
R N E U=w \cdot E U(X)+(1-w) \cdot f\left(C\left(X_{S_{i}}\right)\right)
$$

घ If we assume the individual utility functions to be independent, we can use Equation 16 Keeney 410 \& Raiffa, 1993) to calculate the overall utility for the network:

$$
U(A)=\sum_{i=1}^{n} c_{i} \cdot U_{i}\left(A_{i}\right)
$$

where $A$ is a set of $n$ attributes assumed as mutually utility independent, $U_{i}\left(A_{i}\right)$ is the conditional utility for attribute $A_{i}$, and $c_{i}$ is the relative importance of attribute $A_{i}$. 


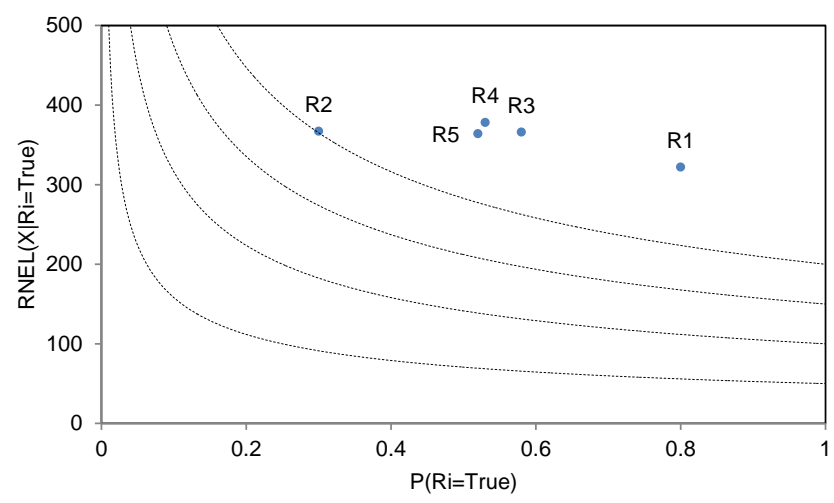

Figure 9: Risk network evaluation under standard configuration (Point S).

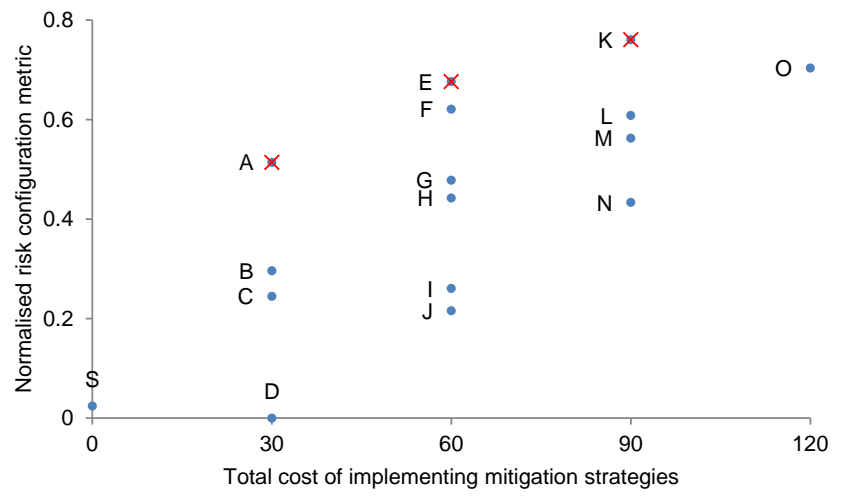

Figure 10: Identification of optimal solutions.

Maximising Normalised Risk Configuration Metric subject to Constraints (related to the Risk Zones). optimal solution for budget greater than or equal to 90 units with configuration of risks shown as Figure A.3. Point $\mathrm{O}$ is not a feasible solution to be considered for optimality. A cross represents an optimal solution. Optimal solutions corresponding to different cost regimes are presented in Table 2 . 


\begin{tabular}{cc}
\hline $\begin{array}{l}\text { Combination of Risk } \\
\text { Mitigation Strategies }\end{array}$ & Cost of Strategies \\
\hline A & $30 \leq$ Cost $<60$ \\
E & $60 \leq$ Cost $<90$ \\
K & Cost $\geq 90$ \\
\hline
\end{tabular}

Table 2: Optimal solutions for the objective function of maximising normalised RCM.

\section{Simulation Study}

An application of the proposed method is demonstrated through a simple supply chain risk network (Garvey et al., 2015) as shown in Figure 11. The supply network comprises one raw material source, two manufacturers, one warehouse and one retailer. Supply chain elements, associated risks and loss values are shown in Table A.3. Although each domain of the supply network may comprise a number of risks and corresponding sources, we consider limited risks for the sake of simplicity. Each risk and mitigation strategy is represented by binary states of True $(\mathrm{T})$ or False $(\mathrm{F})$ and Yes $(\mathrm{Y})$ or No $(\mathrm{N})$, respectively. Assumed (conditional) probability values are shown in Table A.4 and the effectiveness of risk mitigation strategies is represented by values appearing in the shaded cells. Potential mitigation strategies, associated risks and costs are depicted in Table A.5.

\subsection{Results}

It is assumed that the decision maker is risk-neutral. As six potential mitigation strategies were considered for implementation, a total of 64 different combinations of strategies were evaluated as shown in Figure 12. All the points below the solid line represent solutions for which the improvement in risk network expected loss is more than the cost of implementing strategies. Only points $\mathrm{A}(S 6)$ and B $(S 1, S 6)$ are the optimal solutions as all other points in the feasible region (below the solid line) fail to meet the other constraint. Therefore, if the decision maker is only concerned about maximising the reduction in cost adjusted risk network expected loss, an amount of 100 units must be invested for a budget range between 100 and 200 units whereas only the strategies amounting to 200 units must be implemented for a budget regime of 200 units and more. The main problem with implementing these optimal solutions is their exclusive focus on the network wide expected loss without accounting for the configuration of risks corresponding to other feasible solutions. 


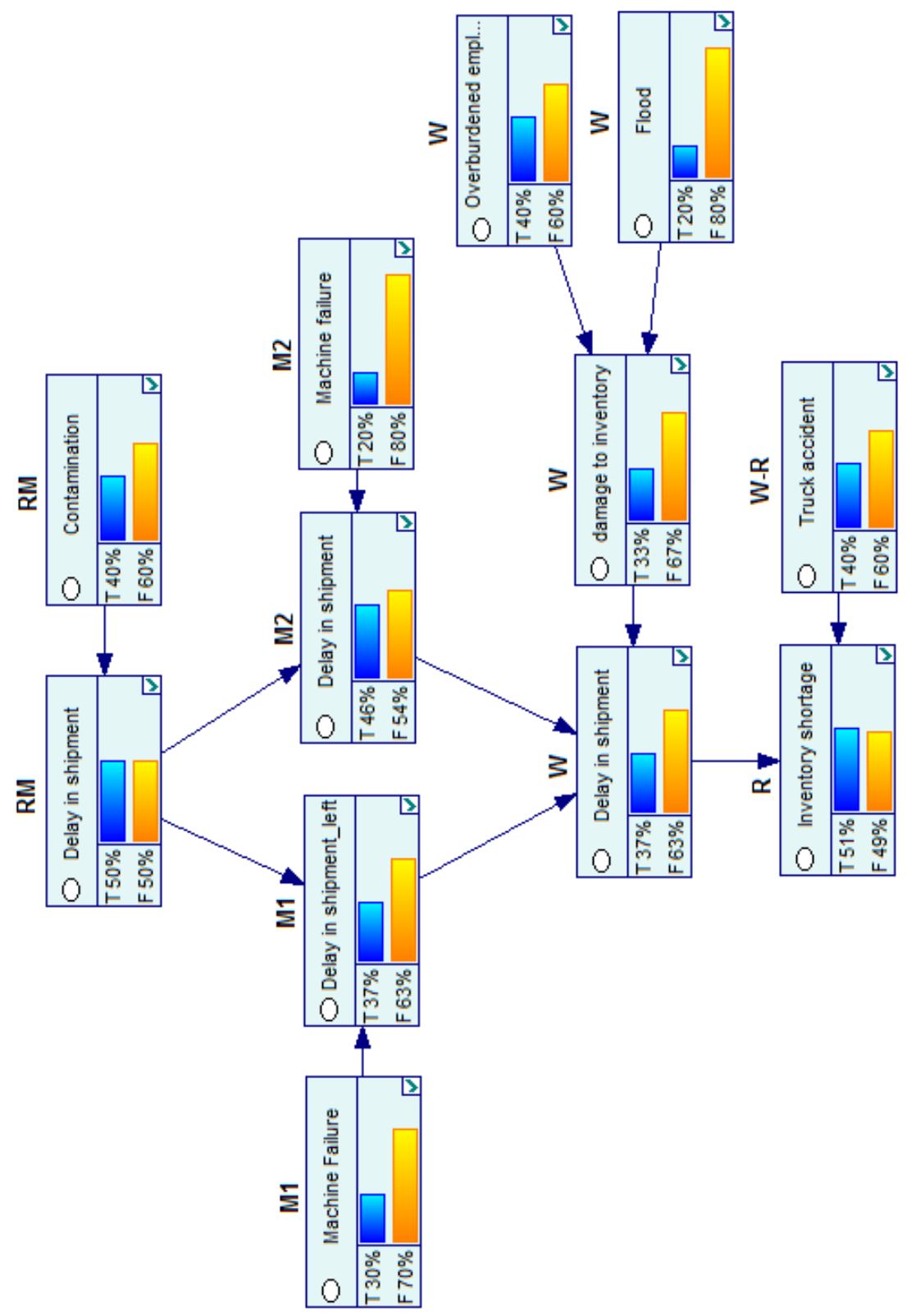

Figure 11: A supply chain risk network modelled in GeNIe (Source: Garvey et al. 2015).

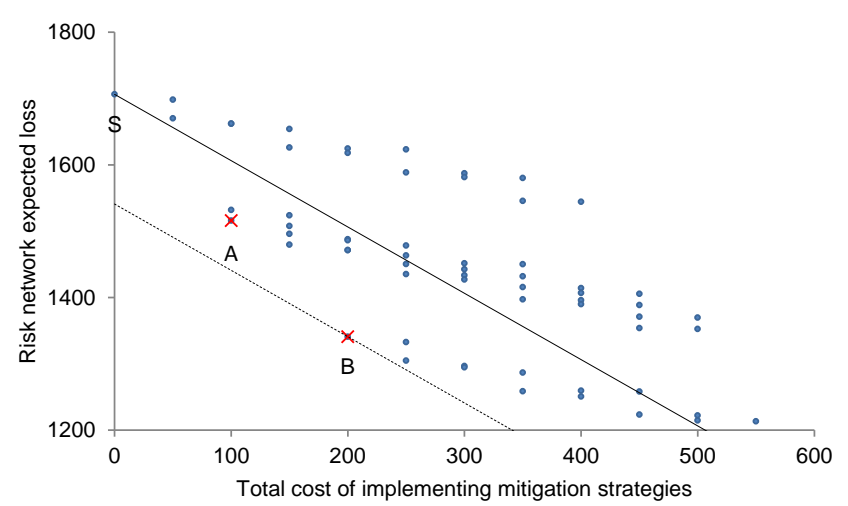

Figure 12: Identification of optimal combinations of strategies. 


\section{Second Approach for Selecting Optimal Strategies (Without Using the Risk Matrix)}

In this approach, a different line of inquiry is adopted where the decision maker utilises the information about cost of strategies and the impact of strategies on the risk exposure (risk network expected loss) to select a portfolio of optimal strategies. With reference to the risk network modelled in Figure 11. all possible combinations of strategies are mapped again in Figure 13 however, here we distinguish between the set of Pareto-optimal solutions (non-dominated solutions) and the dominated solutions specific to different budget constraints that are represented by filled and hollow circles, respectively. The definition of Pareto-optimal set introduced by Spackova \& Straub (2015) is adopted that contains all such combinations of strategies for which there are no other combinations that have simultaneously lower costs and lower risk exposure. Points $\mathrm{O}$ and $\mathrm{P}$ are included in the set of Pareto-optimal solutions; however, for a risk-neutral decision maker, these points fall short of the threshold criterion demanding the equivalence of improvement in risk exposure and the additional investment. For each budget constraint, the point is selected which maximises the perpendicular distance between the solid line and the parallel family of lines. Therefore, for a budget lesser than 200 units, point A is the optimal mix of strategies whereas for all other budget constraints, point B is the optimal solution.

In contrast to a risk-neutral decision maker, a risk-averse individual would have greater concern with regards to the occurrence of risks and therefore, they will prefer to avoid such situations at the cost of enhanced investment. The risk appetite of a risk-averse individual can be modelled through a line with lower gradient (like the solid blue line in Figure 14) which indicates that the individual is willing to invest relatively more than the risk-neutral individual to achieve same reduction in the risk exposure. Similarly, a risk-seeking individual represented by the red line as shown in Figure 14 (with a steeper gradient) would only be willing to invest if the improvement in risk exposure is more than the figure determined through the cost-benefit analysis.

For the blue line, all the solutions included in the Pareto-optimal set are feasible solutions. Depending on the gradient of the line, different points will be optimal subject to the budget constraint. Once

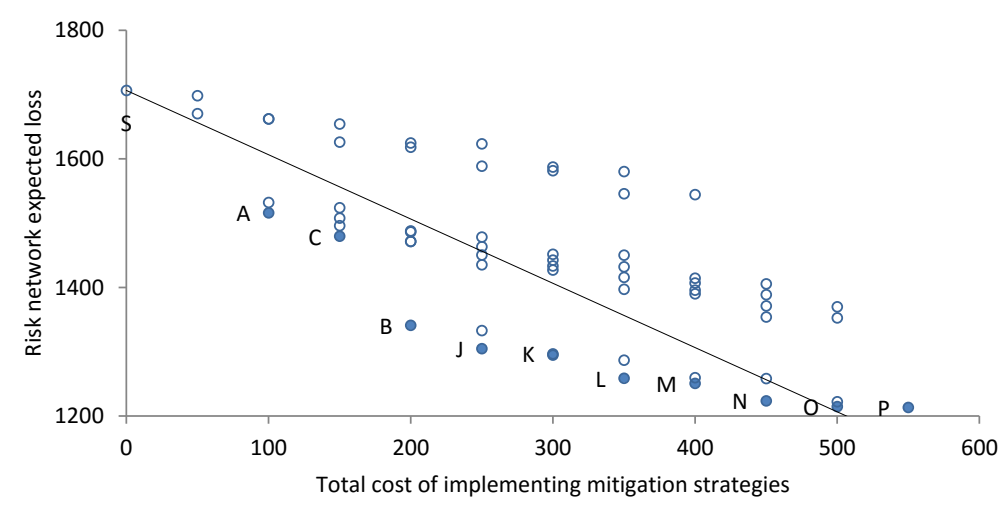

Figure 13: Pareto-optimal solutions (filled circles) and dominated solutions (hollow circles). 


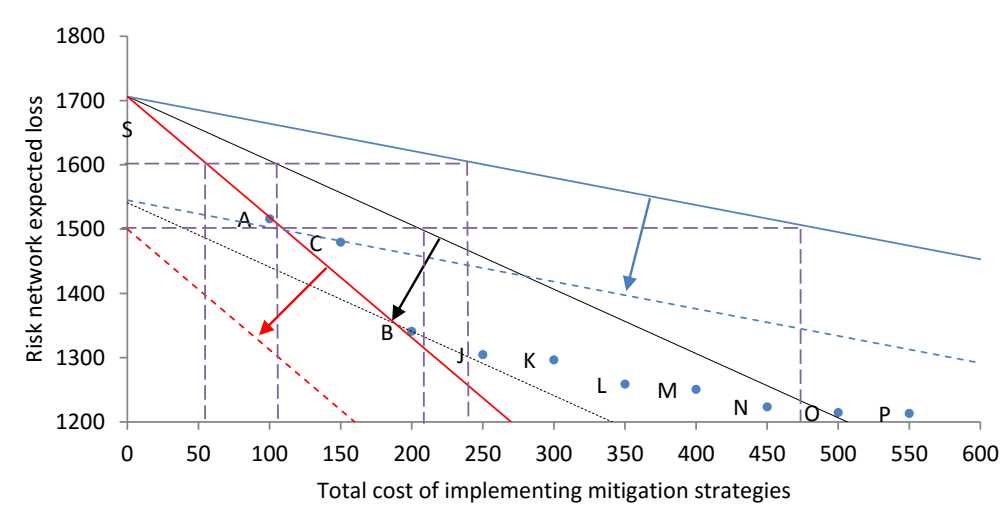

Figure 14: Family of lines representing risk appetite influencing the set of feasible solutions.

the line approaches a gradient of zero, all points will be optimal solutions subject to the respective budget constraint meaning that point $\mathrm{P}$ will be picked for a budget of at least 550 units and similarly, point $\mathrm{O}$ for a budget of at least 500 units but lesser than 550 units. For the red line mapped, it is evident that only point $\mathrm{A}$ is the optimal solution for a budget of at least 100 units.

Another approach to justifying the relevance of trade-off between the improvement in risk exposure and the additional investment specific to the risk appetite is illustrated through a simple example. With reference to Figure 13, a point represents a specific combination of strategies with associated cost and risk exposure across the risk network shown in Figure 11. Risk exposure across the 12 risk events can be represented as:

$$
R N E L=P\left(\bar{R}_{1} \cap \bar{R}_{2} \ldots \bar{R}_{12}\right) . L\left(\bar{R}_{1} \cap \bar{R}_{2} \ldots \bar{R}_{12}\right) \ldots+P\left(R_{1} \cap R_{2} \ldots R_{12}\right) . L\left(R_{1} \cap R_{2} \ldots R_{12}\right)
$$

Where $P\left(\bar{R}_{i}\right)$ and $L\left(R_{i}\right)$ represent probability of risk $R_{i}$ not happening and the loss associated with the occurrence of risk $R_{i}$, respectively.

$$
R N E L=P(\bar{R}) \cdot 0+P(\widetilde{R}) \cdot L(\widetilde{R})
$$

Where $\bar{R}$ is a scenario of no risk realising and $\widetilde{R}$ represents a scenario of at least one risk realising.

$$
R N E L=P(\widetilde{R}) \cdot L(\widetilde{R})
$$

The improvement in $R N E L$ subject to an additional investment helps in reducing the value of $P(\widetilde{R})$ and/or $L(\widetilde{R})$. For a risk-neutral decision maker, the improvement in $R N E L$ must be equal to the additional investment at the minimum. However, the loss value $(L(\widetilde{R}))$ might have reduced by a greater margin in comparison with the change in investment. For example, if a combination of strategies $X[Y]$ yields $P(\widetilde{R})$ and $L(\widetilde{R})$ values of $0.2[0.2]$ and $100[200]$, respectively at a cost of 70[50] units, the risk-neutral decision maker will be indifferent between $X$ and $Y$. However, the risk-averse individual will consider the significance of $X$ in reducing the loss value far greater than the increase 
in investment mainly because the loss values associated with different scenarios might be deleterious to their business. Similarly, a risk-seeking individual would want a greater margin of improvement in $R N E L$ with respect to the same investment made. For the same improvement in $R N E L$ from 1600 to 1500 units as shown in Figure 14, the risk-seeking individual is willing to invest 50 units whereas the risk-neutral (averse) individual would invest 100(240) units.

In order to combine the cost of strategies and associated risk exposure, there is a need to adopt a consistent method of mapping these together on a single scale. For each combination of strategies, we register the improvement in risk exposure and reduction in mitigation cost (negative of cost) with respect to the current configuration of strategies already implemented. It is proposed to use the method of 'swing weights' (Belton \& Stewart, 2002) to determine the relative weight of the two criteria where the decision maker is asked to consider that both improvement in risk exposure and reduction in mitigation cost are at the least preferred states (all risks realised and maximum possible cost of strategies incurred each amounting to the value of 0 ). Subsequently, they are given a scenario that only one of these could be improved to the best possible state and the one picked by them should receive the maximum weight (100) reflecting the significance of that criterion. They are then required to assess the overall value (over a scale from 0 to 100) arising from a swing from 0 (worst state) to 1 (best state) on the other criterion corresponding to the swing from 0 to 1 on the criterion already prioritised. The weights assigned can be normalised to add up to 1 . We define $\beta$ as the weighted sum of improvement in $R N E L$ and reduction in mitigation cost:

$$
\beta=(1-a)(\text { improvement in } R N E L)+a(\text { reduction in mitigation cost })
$$

Where $a$ is a parameter that captures the importance of cost as to how a decision maker may place greater or lower weight on the cost of risk mitigation; when $a=0$, the decision maker is not concerned about the cost of implementing strategies while in the case of $a=1$, they will not consider implementing any additional strategy as the reduction in mitigation cost will be maximum at the current configuration of strategies.

For a risk-neutral decision maker, $a=0.5$ because they want to get the improvement in $R N E L$ to be equal to the additional mitigation cost at the minimum and therefore, $\beta=0$ would represent the threshold where they are willing to invest an additional amount in order to reduce risk exposure. Increasing values of $\beta$ would yield a family of lines where the optimal solution subject to a budget constraint would be tangent to the line with the highest $\beta$. For a risk-averse (seeking) individual, $a$ will be smaller (greater) than 0.5 and $\beta \geqslant 0$ would generate the corresponding family of lines.

Equations of three solid lines shown in Figure 14 can be deduced from Equation 20 as follows:

$$
0=(1-a)\left(R N E L_{S C}-R N E L\right)-a(\text { mitigation cost })
$$




$$
R N E L=\frac{-a}{1-a}(\text { mitigation cost })+R N E L_{S C}
$$

Where 'mitigation cost' accounts for the additional cost with respect to the current cost of strategies implemented and $R N E L_{S C}$ is the risk exposure under the current configuration of strategies.

\section{Discussion} the implications of individual risk scenarios happening. However, the second approach might be viable in the case where a decision maker is not comfortable with the risk matrix based approach and it still 
helps in determining the set of Pareto-optimal solutions and an optimal solution subject to a budget

\subsection{Comparison of the Proposed Risk Matrix Based Method with the Standard Expected Utility based} Method

In the case of a risk network where $N$ risks and $M$ strategies (each having binary states) are interdependent and the utilities associated with different consequences are not mutually independent, critical risk zone to establish if the overall benefits exceed the cost of implementing additional strategies. Therefore, the company would still benefit from the implementation of additional cost-effective strategies resulting from the incorrect partitioning; however, these strategies would not conform to 
the actual risk appetite of the decision maker. Similarly, if the boundaries are incorrectly expanded beyond true limits, the company might be prone to vulnerable risks exceeding their true risk appetite.

\section{Conclusions}

A number of frameworks and modelling tools have been proposed in the literature on SCRM for identifying, assessing and mitigating risks. These studies have been periodically reviewed for directing future research. Focusing on the theme of risk management process/framework, this paper presented a critical review of quality articles. It was established that there is no single study focusing on the SCRM process within an integrated framework of interacting risks and the risk appetite of a decision maker. The articles on literature reviews were also reviewed revealing that even these articles have not realised and emphasised the need for conducting research in this direction.

On the basis of the research gap identified, a new risk management process, namely $R M S C R M$, was introduced. There is a need for bringing a paradigm shift in terms of modelling chains/network of interacting risks and risk sources. Instead of modelling and managing supply chain risks in isolation, researchers must embrace the notion of modelling and managing a network of risks and develop effective and efficient tools for practitioners to adopt in real scenarios. There is also a need for exploring tools that integrate all stages of the risk management process instead of focusing on separate stages (Ho 610 et al. 2015).

Risk measures must be introduced that could capture the network-wide holistic impact of interacting risks. However, optimising the risk network against these measures alone might result in sub-optimal solutions as it is also important to consider the risk appetite of a decision maker. Although EUT provides a standard procedure for decision making under uncertainty, it is not viable to even assess a simple risk network comprising a limited number of risks and strategies. Therefore, we introduced the idea of adapting risk matrix for projecting the configuration of interdependent risks. The risk matrix has already been modified for mapping the risk appetite of a decision maker. However, the main limitation is its exclusive application to independent categories of risks. This paper proposed its adaptation to the context of interdependent risk networks.

In order to present a modelling framework for the proposed $R M S C R M$ process, we introduced a modelling approach grounded in the framework of BBNs. We made use of an existing risk measure, namely $R N E L P M$, and introduced two algorithms for managing supply chain risk network with regard to risk-neutral and risk-seeking/averse decision makers. The algorithms can also be used in the context of other modelling technique and/or risk measures. We demonstrated the meaning of key concepts through an illustrative example. Furthermore, the proposed process was also demonstrated through a simulation study in the context of SCRM. We also introduced a second approach to determine the set of Pareto-optimal risk mitigation strategies where the decision maker needs to establish the trade-off 
between the improvement in risk exposure and the cost of strategies without utilising the risk matrix.

The proposed risk matrix based process can help researchers focus on a new stream of research and risks. In future, empirical studies may be conducted to gauge the feasibility of the proposed modelling framework and determine the associated challenges.

\section{References}

Ackermann, F., Howick, S., Quigley, J., Walls, L., \& Houghton, T. (2014). Systemic risk elicitation: of Operational Research, 238, 290-299.

Aqlan, F., \& Lam, S. S. (2015). Supply chain risk modelling and mitigation. International Journal of Production Research, 53, 5640-5656.

Aven, T. (2011). On the new iso guide on risk management terminology. Reliability Engineering $\mathcal{G}^{\prime}$

Aven, T. (2012). Common Thinking about Risk and Risk Analysis. John Wiley \& Sons, Ltd.

Aven, T. (2015). Risk assessment and risk management: Review of recent advances on their foundation. European Journal of Operational Research, 253, 1-13.

Aven, T., \& Kristensen, V. (2005). Perspectives on risk: review and discussion of the basis for

Belton, V., \& Stewart, T. J. (2002). Value function methods: Practical basics. In Multiple Criteria Decision Analysis: An Integrated Approach (pp. 119-161). Boston, MA: Springer US.

Cavinato, J. L. (2004). Supply chain logistics risks: From the back room to the board room. International Journal of Physical Distribution 83 Logistics Management, 34, 383-387.

Colicchia, C., \& Strozzi, F. (2012). Supply chain risk management: a new methodology for a systematic literature review. Supply Chain Management: An International Journal, 17, 403-418.

Duijm, N. J. (2015). Recommendations on the use and design of risk matrices. Safety Science, 76, $21-31$. 
Elleuch, H., Hachicha, W., \& Chabchoub, H. (2014). A combined approach for supply chain risk management: description and application to a real hospital pharmaceutical case study. Journal of Risk Research, 17, 641-663.

Fahimnia, B., Tang, C. S., Davarzani, H., \& Sarkis, J. (2015). Quantitative models for managing supply chain risks: A review. European Journal of Operational Research, 247, 1-15.

Garvey, M. D., Carnovale, S., \& Yeniyurt, S. (2015). An analytical framework for supply network risk propagation: A bayesian network approach. European Journal of Operational Research, 243, 618-627.

GeNIe (2.0). The decision systems laboratory, genie and smile. retrieved 5 june, 2014, from http://genie.sis.pitt.edu/about.html. URL: http://genie.sis.pitt.edu/about.html.

Ghadge, A., Dani, S., \& Kalawsky, R. (2012). Supply chain risk management: present and future scope. International Journal of Logistics Management, 23, 313-339.

Giannakis, M., \& Papadopoulos, T. (2016). Supply chain sustainability: A risk management approach. International Journal of Production Economics, 171, Part 4, 455-470.

Giunipero, L. C., \& Eltantawy, R. A. (2004). Securing the upstream supply chain: a risk management approach. International Journal of Physical Distribution \&3 Logistics Management, 34, 698-713.

Hallikas, J., Karvonen, I., Pulkkinen, U., Virolainen, V.-M., \& Tuominen, M. (2004). Risk management processes in supplier networks. International Journal of Production Economics, 90, 47-58.

Harland, C., Brenchley, R., \& Walker, H. (2003). Risk in supply networks. Journal of Purchasing and Supply Management, 9, 51-62.

Heckmann, I., Comes, T., \& Nickel, S. (2015). A critical review on supply chain risk -definition, measure and modeling. Omega, 52, 119-132.

Ho, W., Zheng, T., Yildiz, H., \& Talluri, S. (2015). Supply chain risk management: a literature review. International Journal of Production Research, 53, 5031-5069.

Jüttner, U., Peck, H., \& Christopher, M. (2003). Supply chain risk management: outlining an agenda for future research. International Journal of Logistics Research and Applications, 6, 197-210.

Kainuma, Y., \& Tawara, N. (2006). A multiple attribute utility theory approach to lean and green supply chain management. International Journal of Production Economics, 101, 99-108.

Keeney, R., \& Raiffa, H. (1993). Decisions with Multiple Objectives: Preferences and Value Tradeoffs. Cambridge University Press. 
Khan, O., \& Burnes, B. (2007). Risk and supply chain management: creating a research agenda. International Journal of Logistics Management, 18, 197-216.

Khan, O., Christopher, M., \& Burnes, B. (2008). The impact of product design on supply chain risk: a case study. International Journal of Physical Distribution \& Logistics Management, 38, 412-432.

Knemeyer, A. M., Zinn, W., \& Eroglu, C. (2009). Proactive planning for catastrophic events in supply chains. Journal of Operations Management, 27, 141-153.

Lavastre, O., Gunasekaran, A., \& Spalanzani, A. (2012). Supply chain risk management in french companies. Decision Support Systems, 52, 828-838.

Manuj, I., \& Mentzer, J. T. (2008). Global supply chain risk management. Journal of Business Logistics, 29, 133-155.

Micheli, G. J. L., Mogre, R., \& Perego, A. (2014). How to choose mitigation measures for supply chain risks. International Journal of Production Research, 52, 117-129.

Natarajarathinam, M., Capar, I., \& Narayanan, A. (2009). Managing supply chains in times of crisis: a review of literature and insights. International Journal of Physical Distribution 8 Logistics Management, 39, 535-573.

Norrman, A., \& Jansson, U. (2004). Ericsson's proactive supply chain risk management approach after a serious sub-supplier accident. International Journal of Physical Distribution $\&$ Logistics Management, $34,434-456$.

Oehmen, J., Ziegenbein, A., Alard, R., \& Schonsleben, P. (2009). System-oriented supply chain risk management. Production Planning \& Control, 20, 343-361.

Olson, D. L., \& Wu, D. D. (2010). A review of enterprise risk management in supply chain. Kybernetes, 39, 694-706.

Ponomarov, S. Y., \& Holcomb, M. C. (2009). Understanding the concept of supply chain resilience. International Journal of Logistics Management, 20, 124-143.

Qazi, A., Quigley, J., Dickson, A., \& Ekici, S. O. (2017). Exploring dependency based probabilistic supply chain risk measures for prioritising interdependent risks and strategies. European Journal of Operational Research, 259, 189-204.

Qazi, A., Quigley, J., Dickson, A., \& Gaudenzi, B. (2015a). A new modelling approach of evaluating preventive and reactive strategies for mitigating supply chain risks. In F. Corman, S. Vob, \& R. R. Negenborn (Eds.), Computational Logistics book section 39. (pp. 569-585). Springer International Publishing volume 9335 of Lecture Notes in Computer Science. 
Qazi, A., Quigley, J., Dickson, A., Gaudenzi, B., \& Ekici, S. O. (2015b). Evaluation of control strategies for managing supply chain risks using bayesian belief networks. In International Conference on Industrial Engineering and Systems Management (pp. 1146-1154).

Rao, S., \& Goldsby, T. J. (2009). Supply chain risks: a review and typology. International Journal of Logistics Management, 20, 97-123.

Rotaru, K., Wilkin, C., \& Ceglowski, A. (2014). Analysis of scor's approach to supply chain risk management. International Journal of Operations \&5 Production Management, 34, 1246-1268.

Ruan, X., Yin, Z., \& Frangopol, D. M. (2015). Risk matrix integrating risk attitudes based on utility theory. Risk Analysis, 35, 1437-1447.

SA (2009). Risk Management: Principles and Guidelines (AS/NZS ISO 31000: 2009). Standards Australia, Sydney.

Sinha, P. R., Whitman, L. E., \& Malzahn, D. (2004). Methodology to mitigate supplier risk in an aerospace supply chain. Supply Chain Management: An International Journal, 9, 154-168.

Sodhi, M. S., Son, B.-G., \& Tang, C. S. (2012). Researchers' perspectives on supply chain risk management. Production and Operations Management, 21, 1-13.

Spackova, O., \& Straub, D. (2015). Cost-benefit analysis for optimization of risk protection under budget constraints. Risk Analysis, 35, 941-959.

Spekman, R. E., \& Davis, E. W. (2004). Risky business: expanding the discussion on risk and the extended enterprise. International Journal of Physical Distribution \& Logistics Management, 34, 414433.

Tang, C. S. (2006). Perspectives in supply chain risk management. International Journal of Production Economics, 103, 451-488.

Tang, O., \& Nurmaya Musa, S. (2011). Identifying risk issues and research advancements in supply chain risk management. International Journal of Production Economics, 133, 25-34.

Tummala, R., \& Schoenherr, T. (2011). Assessing and managing risks using the supply chain risk management process (scrmp). Supply Chain Management: An International Journal, 16, 474-483.

Tuncel, G., \& Alpan, G. (2010). Risk assessment and management for supply chain networks: A case study. Computers in Industry, 61, 250-259.

Wieland, A., \& Wallenburg, C. M. (2012). Dealing with supply chain risks: Linking risk management practices and strategies to performance. International Journal of Physical Distribution $\mathcal{E}$ Logistics Management, 42, 887-905. 
Appendix A.

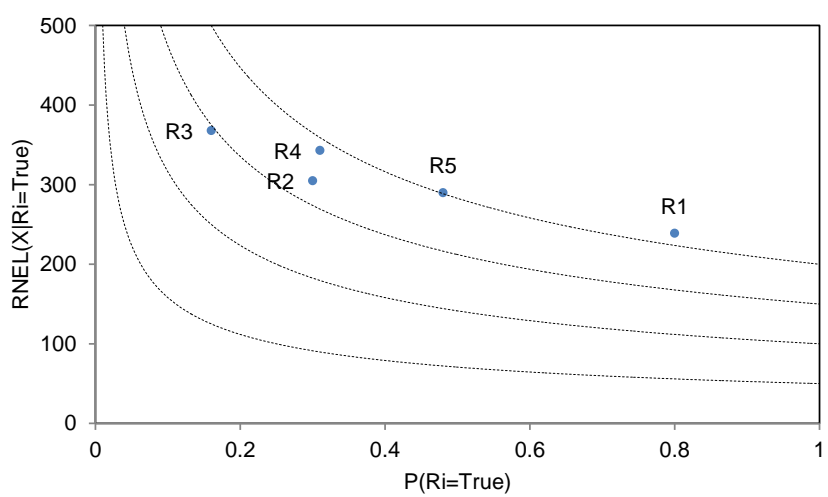

Figure A.1: Risk network evaluation (point A). 


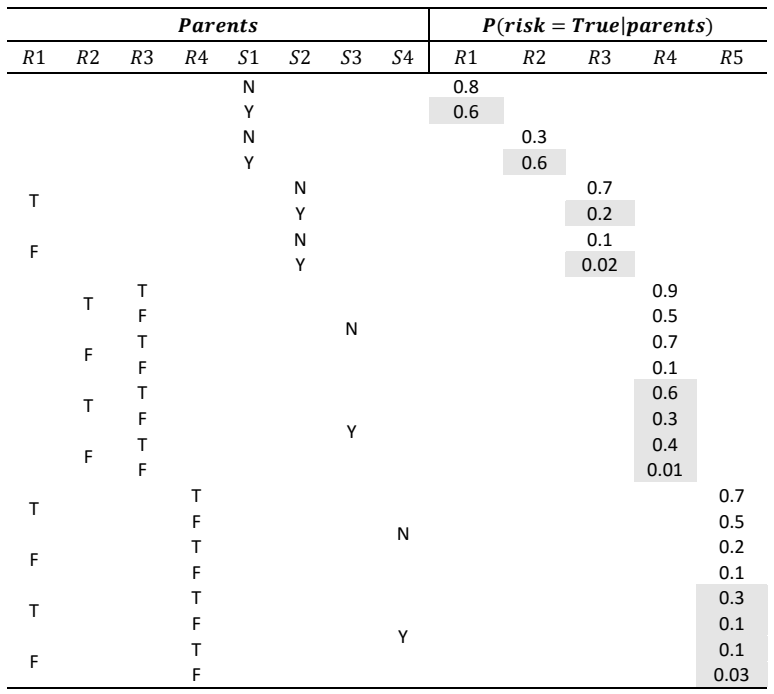

Table A.1: Conditional probability values.

\begin{tabular}{ccc}
\hline $\begin{array}{c}\text { Combination of Risk } \\
\text { Mitigation Strategies }\end{array}$ & $\begin{array}{c}\text { Risk Mitigation } \\
\text { Strategies }\end{array}$ & $\begin{array}{c}\text { Total } \\
\text { Cost }\end{array}$ \\
\hline S & - & 0 \\
A & S2 & 30 \\
B & S4 & 30 \\
C & S3 & 30 \\
D & S1 & 30 \\
E & S2, S4 & 60 \\
F & S2, S3 & 60 \\
G & S3, S4 & 60 \\
H & S1, S2 & 60 \\
I & S1, S4 & 60 \\
J & S1, S3 & 60 \\
K & S2, S3, S4 & 90 \\
L & S1, S2, S4 & 90 \\
M & S1, S2, S3 & 90 \\
N & S1, S3, S4 & 90 \\
O & S1, S2, S3, S4 & 120 \\
\hline
\end{tabular}

Table A.2: Combinations of risk mitigation strategies.

\begin{tabular}{lll}
\hline Supply Chain Element & Risk & Loss \\
\hline \multirow{2}{*}{ Raw Material Source (RM) } & Contamination (R1) & 200 \\
& Delay in Shipment (R2) & 400 \\
\hline \multirow{2}{*}{ Manufacturer-I (M1) } & Machine Failure (R4) & 200 \\
& Delay in Shipment (R5) & 400 \\
\hline \multirow{2}{*}{ Manufacturer-II (M2) } & Machine Failure (R3) & 200 \\
& Delay in Shipment (R6) & 400 \\
\hline \multirow{2}{*}{ Warehouse (W) } & Overburdened Employee (R7) & \\
& Damage to Inventory (R8) & 500 \\
& Delay in Shipment (R9) & 600 \\
\hline Warehouse to Retailer (W-R) & Flood (R12) & 500 \\
\hline Retailer (R) & Truck Accident (R10) & 800 \\
\hline
\end{tabular}

Table A.3: Supply chain elements, risks and loss values. 


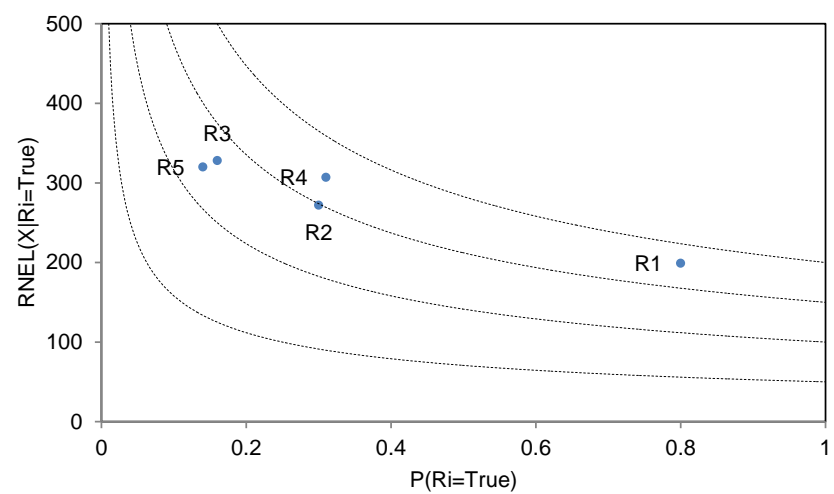

Figure A.2: Risk network evaluation (point E).

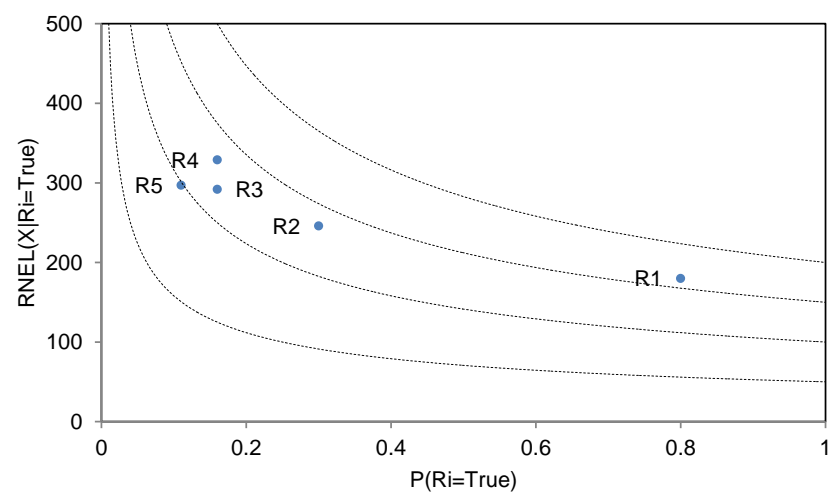

Figure A.3: Risk network evaluation (point K).

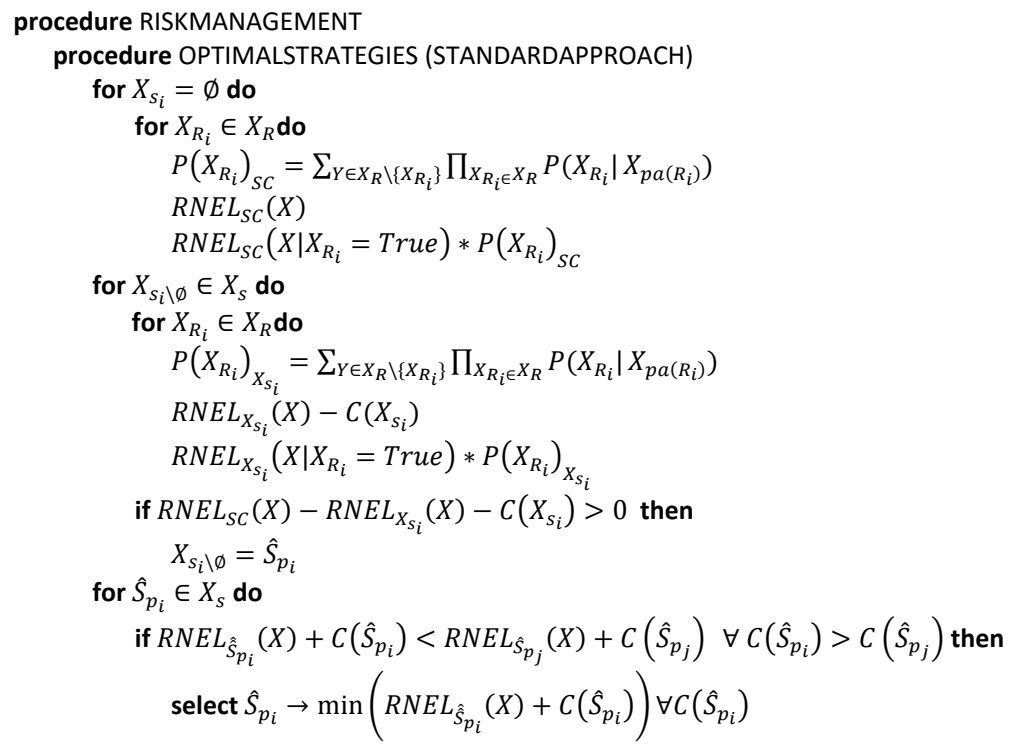

Figure A.4: Risk network management for risk-neutral decision maker. 


\begin{tabular}{llll|llllll}
\hline \multicolumn{4}{c|}{ Parents } & \multicolumn{5}{c}{ P(risk= True |parents) } \\
\hline$R 1$ & $R 2$ & $R 3$ & $R 4$ & $R 1$ & $R 2$ & $R 3$ & $R 4$ & $R 5$ & $R 6$ \\
\hline \multicolumn{1}{c}{} & 0.4 & & & & & \\
& & 0.1 & & & & &
\end{tabular}

T

0.8

0.2

0.1

0.3

\begin{tabular}{lllll} 
T & & T & 0.7 & \\
T & & F & 0.4 & \\
F & & T & 0.6 & \\
F & & F & 0.1 & \\
T & T & & & 0.9 \\
T & F & & & 0.6 \\
F & T & & 0.5 \\
F & F & & 0.2 \\
\hline
\end{tabular}

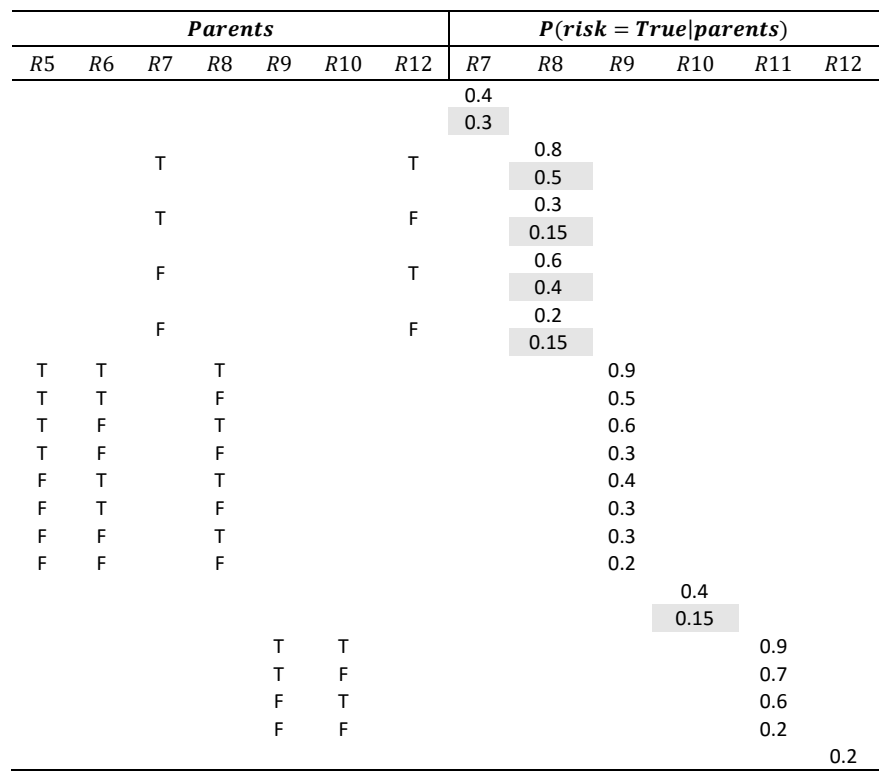

Table A.4: (Conditional) probability values.

\begin{tabular}{clcc}
\hline $\begin{array}{c}\text { Risk Mitigation } \\
\text { Strategy }\end{array}$ & \multicolumn{1}{c}{ Description } & Associated Risk & Cost \\
\hline S1 & Quality Assurance Program & R1 & 100 \\
S2 & Scheduled Maintenance Program & R3 & 50 \\
S3 & Scheduled Maintenance Program & R4 & 100 \\
S4 & Scheduling Software and Monitoring & R7 & 50 \\
S5 & Program & R8 & 200 \\
S6 & Early Warning System & R10 & 100 \\
\hline
\end{tabular}

Table A.5: Potential risk mitigation strategies, associated risks and cost. 


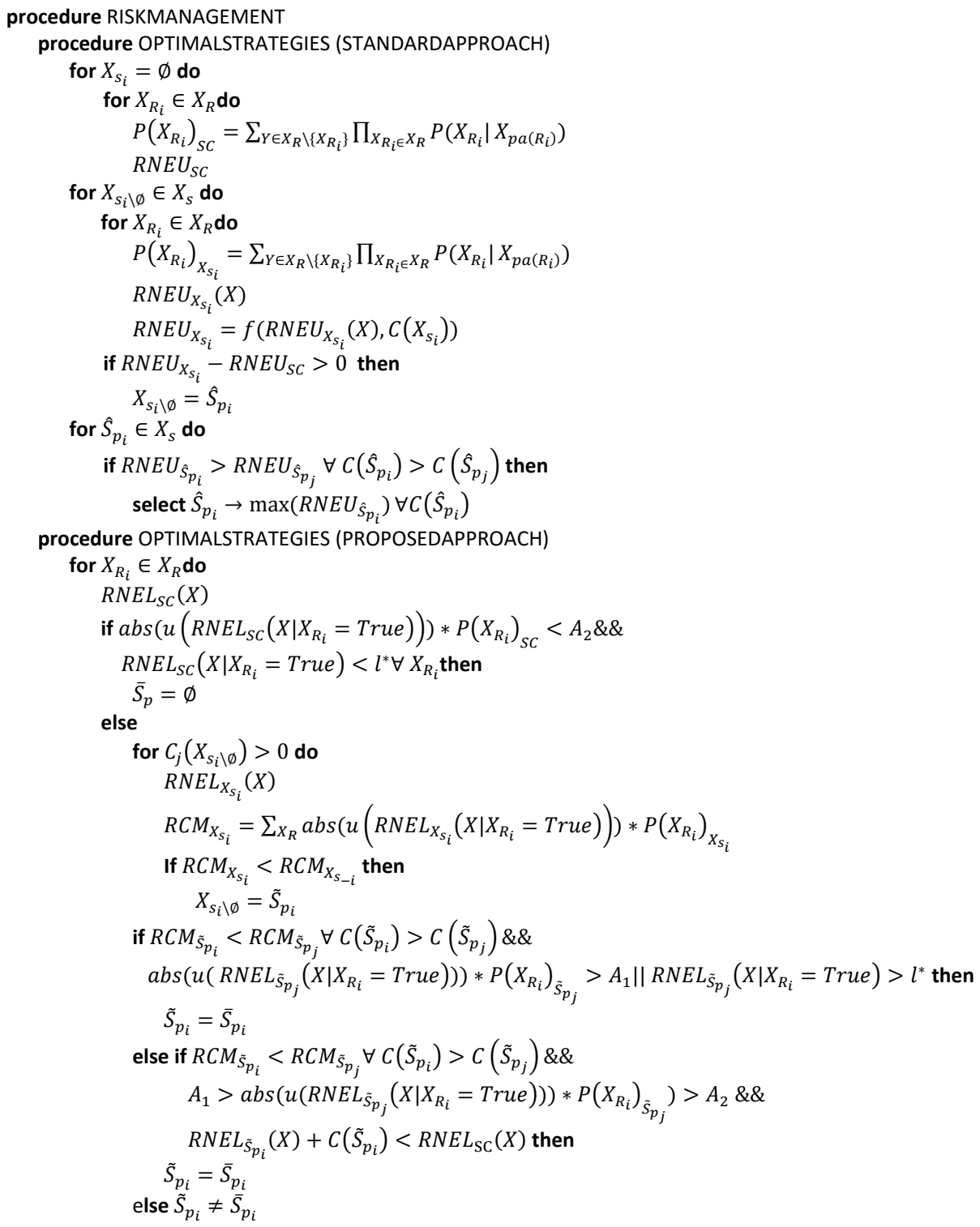

Figure A.5: Risk network management for risk-averse or risk-seeking decision maker. 